\title{
Lexicon that Survives, Changes, and Innovates in Sanur Area: Ecotourism Linguistics
}

\author{
I Nyoman Kardana, I Nyoman Muliana, I Made Astu Mahayana, I Gusti Ngurah Adi Rajistha \\ \{ikardana@yahoo.com\}
}

English Department, Universitas Warmadewa

\begin{abstract}
Eco-linguistic research has been conducted quite often in recent years, though on the lexicon in one particular area. The purpose of this study is to examine the lexicon treasures in Sanur tourism area. This location is selected since the area is at the risk of being affected negatively by the development of tourism in Bali due to globalization. The development of information technology and the progress in tourism might change the behavior and social attitudes of the society, as well as the biological environment of an area. This study examines the impacts of the development of tourism in Sanur tourism area by examining the ecotourism linguistics. Also, it analyzes the lexicon that survive and become extinct and innovative in Sanur tourism area. The data used is in the form of written and spoken information. They were collected through observation and interview, supported by recording techniques. The results show that many lexicons are found in relation to the biological environment in Sanur area. Although most of them survive today, some have been affected negatively, becoming rare and extinct.
\end{abstract}

Keywords: Sanur, ecotourism linguistics, lexicons, environmental change

\section{Introduction}

Tourism in Bali has been developing since the colonial era in Bali. Since then many foreigners, especially Dutch people have lived in Bali for a long time to enjoy the nature and culture of Bali. The presence of the Dutch in Bali was not only as invaders but they had also helped to promote Bali abroad, and since then European and American people had come and arrived in Bali. This has had a positive impact on the progress of Balinese civilization. Up to now there have been several Dutch and other foreigners marrying Balinese ladies and living in Bali. Their presence in Bali has continuously introduced Bali to the international world. This can be done as they have sufficient access and infrastructure to do so.

The arrival of tourists has resulted in a change in the environment on the island of Bali, both the physical environment and social environment. A very striking environment is the change in the physical environment such as the conversion of land which was originally a paddy field into an inn building, a restaurant and a handicraft shop. The beach which was originally used as a fishing spot to catch and hang fish for fishermen has changed its function as a beach tour such 
as surfing, canoeing and sunbathing. The ship which was originally used to catch fish, is now used as a means of transportation to enjoy the scenery in the sea or to watch dolphins in the middle of the sea. This condition is very interesting to study in terms of eco-linguistics by using semantic relations as the basis for collecting lexicons related to environmental change. Haugen says that the ecology of language is determined by people who learn, use, and convey the language to others [1], [2]. Meanwhile Halliday states that language and environment are two things that influence each other [3]. For example, in Sundanese, the metaphor uses lexicons of fauna [4]. Changes in language, both in the field of the lexicon and grammar, cannot be separated from changes in the natural and social (cultural) environment of its people. On one hand, environmental change has an impact on language change, and on the other hand, people's behavior towards their environment is influenced by the language they use [5]. Eco-linguistics is the study of language and environment with three aspects of study, namely biological, sociological, and psychological. Because this study is related to language and environment, the focus of the data to be examined is the lexicon relating to the environment. With so many environmental criteria when viewed from biology, namely the terrestrial, oceanic, mountainous or biotic and abiotic environment, this research focuses on lexicon related to tourism. Thus, this study aims to examine the lexicon that survive, become extinct, and which innovate in Sanur tourism area.

\section{Methods}

Data of this research is in the form of empirical data obtained orally and direct observations found at the research location, Sanur tourism area as one of the well-known and developing tourist areas in Bali. Research data were collected through observation and interview methods along with the required techniques. This method requires recording and photo techniques to store the marks and utterances that were found related to the topic to be studied. Then the interview method was used to obtain data from selected informants. This research focuses on the biological environment and the data was classified into types of lexicon, in the form of nouns, adjectives, verbs, or adverbs. Next, the existence data (lexicon) were examined in order to know if they have already become extinct, have survived, or have innovated. After analyzing the collected data, the current lexicon can be classified into those that have changed, still survive, and have innovated to other forms. The insistence of outside cultures and the influence of information technology have high roles for the situation and condition. In addition, the changes in behavior and ideology of the community are also found compared to before the great development occurred in the tourism area.

\section{Results And Discussion}

\subsection{The Surviving Lexicons and Their Functions}

From a language point of view, surviving flora and fauna provide a lexicon of flora and fauna that still exists today despite changes in the environment in Sanur area and changes in the patterns of life of the people. The existence of flora and fauna in the region clearly influences language. Language that arises from the existence of objects, in this case flora and fauna, are a reflection of these objects. In other words, language or lexicon about flora and fauna exists 
because of the existence of these flora and fauna and have direct contact with the community. This is in line with the use of the names of flora and fauna in beblabadan 'metaphor' because of their existence in the environment [6]. As Bang and Døør explained in the dialogue model they created, that language has three interrelated dimensions. These dimensions include biological dimensions, sociological dimensions, and ideological dimensions. In this case, the lexicon of flora and fauna are a biological dimension of language [7]. The surviving lexicons of flora and fauna indicate the survival of the flora and fauna in Sanur area. This research has drawn a line that shows the relationship of biological dimensions that occur between the environment and the language used. This diagram shows the condition of the flora and fauna in Sanur area.

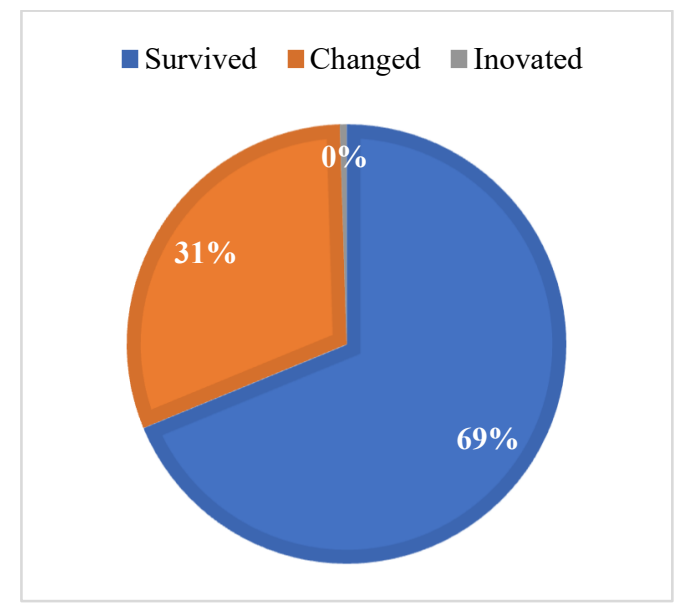

Diagram (1). The Condition of Flora and Fauna in Sanur Area

Based on the diagram above, it can be seen that $69 \%$ flora and fauna still survive, $31 \%$ flora and fauna have been changing, and $0 \%$ flora and fauna innovates. Based on the research there are 79 faunas whose existence still exists in Sanur area. This certainly means that the existence of the fauna is a biological dimension of language, that is, the language exists because of the existence of the fauna in the lives of Sanur people. In this case, the diversity of fauna species in Sanur indirectly enriches the lexicon and language vocabulary, especially the Balinese language. The durability of the lexicons is inseparable from the influence of the fauna. Most of the fauna are very useful for people's lives. Some faunas function as food, such as chicken, pork, beef, several types of fish including shrimp. In addition, some faunas also function as pets such as dogs and cats. There are also some fishes that are made into ornamental fish. Some of the others are wild animals that are not useful but their presence is commonly found in the area. In addition to the above functions, fauna such as chickens, pigs, dogs, etc., also function as religious facilities. In addition to the types of fauna that survive in the Sanur region despite changes in the environment and patterns of community life, there are many types of flora that still survive as well today. Based on the research, there are 62 floras which still exist up to now, and the floras have direct benefits for people in Sanur area. The floras found in the area are flora which can be utilized by the community either as food, ritual facilities, or those which are very useful for the fauna in the area. Some of the existing floras relate to fibrous and nutritious food. These floras include kale, banana, soursop, papaya, coconut, and seaweed. The floras can be 
consumed clearly and the existence of these floras is still often found in Sanur area. The flora that is useful for the human life will of course always exist and survive [8]. Bali, which is famous for its culture, naturally uses flora as a means of ritual. Some of the flora above is closely related to Hindu religious rituals and this is also a reason why the flora still survives untill today. Although many changes occur as an impact of tourism, the people of Sanur still maintain Balinese culture by directly maintaining the flora used in religious rituals. The flora is like the types of flowers that include hibiscus flower, cempaka, sandat, etc. In addition, there are also betel leaves and pandanus.

\subsection{The Changing Lexicons and Their Functions}

In addition to the flora and fauna that still exist in Sanur area, it turns out that based on research it was found that many flora and fauna have experienced a negative change. As explained earlier, negative changes lead to rare and extinct conditions. The condition of flora and fauna certainly affects aspects of language. In other words, the higher the rarity level of a flora and fauna, the language that refers to this form will be unknown. If the flora and fauna begun to extinct, then the extinction does not occur only in terms of the flora and fauna but it also happen to the extinction of language. The following diagram shows the condition of lexicons that change into rare and extinct condition.

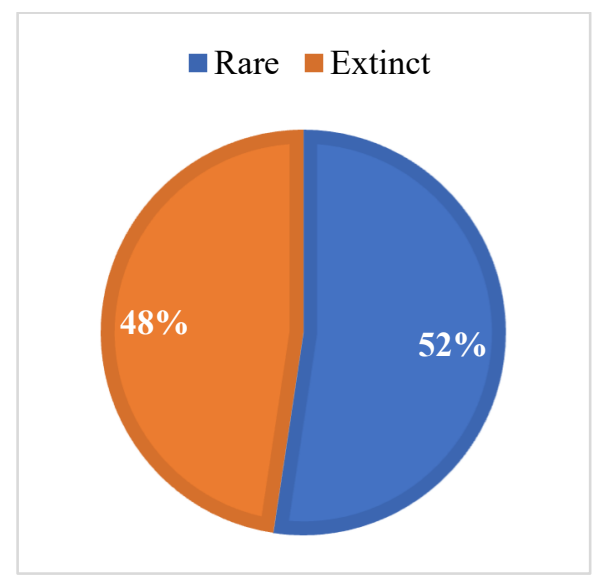

Diagram (2). Flora and Fauna Change into Rare and Extinct

There are several faunas which are categorized in rare conditions. This is influenced by various factors. Rare fauna directly affects the level of language use that refers to the fauna. Based on the research, it can be stated that the scarcity of fauna is influenced by various factors. This rare condition can be caused by the changes in people's lives, from originally fishermen into tourism agents. In addition, scarcity is caused by changes in environmental conditions that are adapted to the social conditions of the community. Due to changes in environmental conditions, some fauna may not be able to be maintained in the area. This scarcity is also caused by large-scale exploitation of the environment and the fauna as well.

One example of fauna that is classified as a rare condition is jaran (horse). At first, this fauna was used as a traditional means of transportation, but along with the development of Sanur as a tourism area, jaran was rarely used, and only maintained in a few places. Another example is the turtle. This fauna is exploited on a large scale before experiencing a rare condition. This 
clearly has a big impact on the number of sea turtles in the Sanur area. Likewise, with other fauna that were eliminated due to changes in environmental conditions, when the wild began to turn into hotels, lodging, to restaurants to support tourism needs.

Public awareness plays an important role in the preservation of the fauna in the future. One form of preservation that has been carried out is the creation of turtle breeding sites, the creation of habitat for marine fauna through artificial coral reefs, and greening in several areas of Sanur. Public awareness has begun to grow along with the direction of green tourism that is more attractive to tourists. In addition to fauna that experience changes in the negative direction, some floras are also not immune from this condition. These floras also enter into a rare condition due to several factors. The factors are changes in socio-economic conditions of society, changes in environmental conditions, and the use of flora for the lives of Sanur people.Changes in socioeconomic conditions can affect the existence of flora in one area. This is seen in Sanur area. Some flora which is useful as a medicine such as kumis kucing and lemo are rarely found today. This is not caused by the reduced benefits of the flora but is influenced by modern medicines which are faster in the healing process. It cannot be denied that traditional medicine provides a longer healing effect compared to modern medicine. This clearly greatly influences the existence of these flora in the Sanur area. In other words, socio-economic conditions of people who are getting better with high routines clearly need medicines that have a faster healing effect, easier to find, and does not need a processing process. If this condition continues to occur, gradually the young generation will not know that the flora around them is flora that has great benefits for their lives. In this case, modernization can slowly replace traditional behavior [9].

Environmental conditions that change into tourist areas, directly begin to affect the existence of these floras. Only flora that has a relationship with tourism will continue to survive. Conversely unrelated, will gradually experience rare conditions and then extinction. In other words, these floras can only be found in the book that documents it, there is language without form. Scarcity that occurs in these floras is strongly influenced by the factor of the use of these flora for life with the current conditions. In the past this flora existed because Sanur was a fishing area. Many trees at least function as a shelter. In the age when the land is getting narrower, the flora which is felt to be less useful will be removed. Obviously, this is what causes rare conditions and even extinction. Rare conditions that last for several years can cause extinction. Extinction means that the flora and fauna are no longer able to maintain their existence in an area. In Sanur area, it was found that some flora and fauna have undergone a change into this extreme negative condition.

Many factors can cause this condition, one of which is the destruction of habitats or nature where these flora and fauna live. Extinction as previously described is a condition where fauna cannot maintain their existence in the Sanur area. This can be caused by the loss of fauna habitat, land conversion, and the usability of the fauna for the people of Sanur. Habitat that was originally a beautiful nature on the coast is a habitat for several types of animals. Habitat of these fauna began to be eroded by the construction of tourism facilities. This of course causes the fauna unable to adjust to the new environment that is filled with human activities.

Land conversion, from a small number of settlements to hotels, restaurants, tourist objects, etc., causes natural land to decrease. With this land conversion, some fauna species cannot maintain their existence. A factor that often causes changes in fauna conditions is the usability factor. Fauna assessed as having no benefit to society will begin to be ignored. So that gradually, the fauna population decreases and eventually becomes extinction. 
Not only had the fauna that experienced this extreme condition, but also several types of flora also experienced extinction. It can be known that the flora can be said not to be too often in contact with coastal communities who generally used to work as fishermen. Some floras were actually beneficial to the community such as medicine and means of Hindu religious rituals such as water hyacinth and fruit. In addition, there are also flora that can be consumed like boni. The ancient cotton tree is also a flora that was usually used as an ingredient in making mattresses or pillows in ancient times.

The factors that affect the extinction of these floras include changes in the patterns of life of the Sanur community, land conversation, and the utilization factor of a flora on the lives of Sanur people. These factors slowly affect the existence of these flora. Changes in the patterns of life of Sanur people greatly affect the existence and existence of extinct flora. Changes in life patterns are shown by changes in the profession of Sanur people who initially were mostly fishermen switched professions to become tourism agents. Changes in the profession are certainly influenced by land conversion. The land began to be used as a supporting facility for tourism. Hotels, restaurants and other facilities began to be built. Of course, this also affects the reduction of these flora until finally the flora is extinct in the area. In addition, the benefits of these flora to the community are felt less then began to be forgotten and replaced by new things related to tourism. Not having direct contact with the community continually causes these floras to experience these extreme conditions.

Based on the analysis of the lexicon that has changed, the change is more negative in the direction of a rare condition followed by extinction. Such conditions, the loss of the existence of flora and fauna, certainly directly affect the language. Language is created based on the existence of something whichever likes. The condition of the language that is created when the existence of something starts to become rare does not indicate the extinction of the lexicon. The lexicons are still known, but not everyone knows the form of the lexicons in question. If the existence of something, flora and fauna, in extinct conditions there are two possibilities that occur in the language that refers to the flora and fauna, namely (1) the existence of flora and fauna is only found in the language so that the physical form of the language is no longer found, and (2) the language about flora and fauna began to be forgotten until it caused the extinction of the lexicon. It is clear that the second condition is very alarming, not only for the existence of the flora and fauna experiencing extinction but the existence of language or lexicon about the flora and fauna will also become extinct.

\subsection{The Innovative Lexicon and Its Function}

Based on the result of the research, only one flora was found to be innovated. This innovation is influenced by human intervention, so it is not entirely naturally experienced by the flora. Coconut tree (nyuh) is a flora that experiences innovation. This flora innovation is caused by human action. The innovation in question is the emergence of coconut bonsai which functions as a very popular ornamental plant lately. Slang language which is created from the existence of this bonsai is bonkla. The term is very commonly used by people who explore making bonsai. Bonkla is an acronym of bonsai kelapa "coconut bonsai". This word is very popular among the population of bonsai. Thus, with the existence of certain innovations on a flora, at the same time the language of the innovation will also emerge, although only in the form of slang is used by these groups. 


\section{Conclusions}

Based on the results of the research, several conclusions can be drawn relating to the treasures of biological lexicon in Sanur area. There are many lexicons related to the biological environment in Sanur area. Many of these lexicons still survive today, but a few have experienced changes in the negative, rare and extinct. But there is a flora that shows innovation. This is very much influenced by environmental conditions which in general have now become a tourism area. Of course, this has caused many changes in terms of the existence of flora and fauna to affect language that refers to them. Flora that innovates shows the existence of a new type of flora that gives rise to new languages that are only used by certain groups, it is bonkla. There are several factors that affect the existence of flora and fauna in Sanur area. These factors include changes in the profession occupied by the community due to the conversion of land into supporting tourism facilities. Besides, the utilization factor of flora and fauna also influences the condition and existence of the flora and fauna. Flora and fauna considered useful as food ingredients or as part of the offerings or ritual facilities are also the factors. This is in line with what has been found in Kuta Lombok [10]. To support flora and fauna conservation, media bias plays such a vital role [11].

\section{References}

[1] E. Haugen, "The Ecology of Language: Essays by Einar Haugen," in The ecology of language, based on The Stigmata of Bilingualism, Stanford: Stanford University Press, 1972, pp. 324-329.

[2] E. Haugen, "The ecology of language," in The Ecolinguistics Reader: Language, Ecology and Environment, Fill, A.,., London: Continum, 2001, pp. 57-66.

[3] M. A. K. Halliday, "New ways of meaning: The challenge to applied linguistics," in The Ecolinguistics Reader: Language, Ecology and Environment, Fill, A.,., London: Continuum, 2001, pp. 175-202.

[4] W. Suktiningsih, "Leksikon Fauna Masyarakat Sunda: Kajian Ekolinguistik," RETORIKA J. Ilmu Bhs., vol. 2, no. 1, pp. 142-160, 2016.

[5] A. Fill and P. Muhlhausler, The Ecolinguistics Reader: Language, EcologyandEnvironment. London: Continum, 2001.

[6] I. G. N. A. Rajistha, "Beblabadan Bahasa Bali dalam Perspektif Ekolinguistik," RETORIKA J. Ilmu Bhs., vol. 2, no. 1, pp. 79-94, 2016.

[7] A. V. Lindø and J. Bundsgaard, Dialectical Ecolinguistics Three Essays for the Symposium 30 Years of Language and Ecology. Odense: University of Odense, 2000.

[8] V. Genua, "Khazanah Leksikon Tanaman Pangan Etnik Nagakeo: Kajian Ekolinguistik," in Simposium Internasional Bahasa-Bahasa Lokal, Nasional dan Global, 2016.

[9] W. J. Santoso, "Analisis Sosio-Ekono-Ekolinguistik terhadap Pemertahanan Leksikon Tanaman Tradisonal untuk Bumbu Masak bagi Mahasiswi di Kota Semarang," J. Pendidik. Bhs. dan Sastra Indones., vol. 2, no. 2, pp. 69-76, 2017.

[10] D. Anita, A. M. Mbete, and H. Mandala, "Ecolexicon Wealth of Nautical Expression in Kuta Lombok Society (An Environment-Based Learning Supplement for Elementary School)," Int. Res. J. Eng. IT Sci. Res., vol. 4, no. 3, pp. 17-22, 2018. 
[11] F. Zulmi, "Keberpihakan Media terhadap Isu Pelestarian Lingkungan Hidup,” J. KATA, vol. 1, no. 2, pp. 101-108, 2017. 